\title{
Doubly-Fed Induction Generator for Variable Speed Wind Energy Conversion Systems- Modeling \& Simulation
}

\author{
B.Chitti Babu , K.B.Mohanty
}

\begin{abstract}
The aim of this paper is to present the complete modeling and simulation of wind turbine driven doubly-fed induction generator which feeds ac power to the utility grid. For that, two pulse width modulated voltage source converters are connected back to back between the rotor terminals and utility grid via common dc link. The grid side converter controls the power flow between the DC bus and the AC side and allows the system to be operated in sub-synchronous and super synchronous mode of operation. The proper rotor excitation is provided by the machine side converter. The complete system is modeled and simulated in the MATLAB Simulink environment in such a way that it can be suited for modeling of all types of induction generator configurations. The model makes use of rotor reference frame using dynamic vector approach for machine model.
\end{abstract}

Index Terms - doubly-fed induction generator (DFIG), pulse width modulation (PWM), dynamic vector approach, utility grid, wind energy conversion systems,

\section{INTRODUCTION}

The conventional energy sources are limited and have pollution to the environment. So more attention and interest have been paid to the utilization of renewable energy sources such as wind energy, fuel cell and solar energy etc. Wind energy is the fastest growing and most promising renewable energy source among them due to economically viable [1-8]. In India, the total installed capacity of wind power generation is 8754 MW in the year 2008.By the end of 2012, the total installed capacity is going to be reached to $12000 \mathrm{MW}$ according to ministry of new and renewable energy, India and total installed capacity of wind energy is estimated to be more than $160 \mathrm{GW}$ [WWEA] all around the world. There were several attempts to build large scale wind powered system to generate electrical energy. The first production of electrical energy with wind power was done in 1887 by Charles brush in Cleveland, Ohio.DC generator was used for power production and was designed to charge the batteries. The induction machine was used at the first time in 1951 .

Manuscript received July 4, 2009. This work was supported in part by the National Mission on Power Electronics Technology under the Departmnet of Information Technology; India under the Project Wind Energy Harnessing B.Chitti Babu is with the National Institute of Technology, Rourkela, INDIA. (corresponding author to provide phone: 91-6612462417; e-mail: bcbabunitrk1@ieee.org).

K.B.Mohanty is with the Electrical Engineering Department, National Institute of Technology, Rourkela, INDIA.

(e-mail: kbmohanty@nitrkl.ac.in).
Many applications of wind power can be found in a wide power range from a few kilowatts to several megawatts in small scale off-grid standalone systems or large scale grid-connected wind farms. Recently Enercon constructed a wind turbine of $4.5 \mathrm{MW}$ with rotor diameter of 112.8 meters. Due to lack of control on active and reactive power, this type of dispersed power generation causes problems in the electrical connected system. So this requires accurate modeling, control and selection of appropriate wind energy conversion system.

During last two decades, the high penetration of wind turbines in the power system has been closely related to the advancement of the wind turbine technology and the way of how to control. Doubly-fed induction machines are receiving increasing attention for wind energy conversion system during such situation. because the main advantage of such machines is that, if the rotor current is governed applying field orientation control-carried out using commercial double sided PWM inverters, decoupled control of stator side active and reactive power results and the power processed by the power converter is only a small fraction of the total system power. So doubly-fed induction machine with vector control is very attractive to the high performance variable speed drive and generating applications [1-4]. With increasing penetration of wind-derived power in interconnected power systems, it has become necessary to model the complete wind energy systems in order to study their impact and also to study wind power plant control. In this paper, an attempt to develop a dynamic model of induction machine which can be simulated as both motoring and generating mode when testing control strategies. Through the model developed in this paper can be used for simulating all types of induction generator configurations. The choice of synchronous rotating reference frame makes it particularly favorable for the simulation of doubly-fed configuration in transient conditions. The induction machine is modeled in vectorized form in the synchronous reference frame. The speed is adjusted by the turbine pitch control to maximize the power generated at a given wind speed. A complete simulation model is developed for such machine under variable speed operation using MATLAB Simulink environment. Section I describes the modeling of wind turbine for different wind velocities. Section II describes the vectorized dynamic modeling of DFIG.Section III describes the modeling of PWM rectifier which feeds power to the utility grid via PWM 
inverter from the rotor. Section IV describes the modeling of two levels PWM voltage source inverter which synchronized with the grid. Final chapter involves the general results and discussion followed by conclusion.

\section{BASIC CONCEPTS AND Wind TURBInE MOdELING}

Wind turbines convert the kinetic energy present in the wind into mechanical energy by means of producing torque. Since the energy contained by the wind is in the form of kinetic energy, its magnitude depends on the air density and the wind velocity. The wind power developed by the turbine is given by the equation (1) [1-10]:

$$
P=\frac{1}{2} C_{P} \rho A V^{3}
$$

where $C p$ is the Power Co-efficient, $\rho$ is the air density in $\mathrm{kg} / \mathrm{m}^{3}, A$ is the area of the turbine blades in $\mathrm{m}^{2}$ and $V$ is the wind velocity in $\mathrm{m} / \mathrm{sec}$. The power coefficient $C p$ gives the fraction of the kinetic energy that is converted into mechanical energy by the wind turbine. It is a function of the tip speed ratio $\lambda$ and depends on the blade pitch angle for pitch-controlled turbines. The tip speed ratio may be defined as the ratio of turbine blade linear speed and the wind speed

$$
\lambda=\frac{R \omega}{V}
$$

Substituting (2) in (1), we have:

$$
P=\frac{1}{2} C_{P}(\lambda) \rho A\left(\frac{R}{\lambda}\right)^{3} \omega^{3}
$$

The output torque of the wind turbine $T_{\text {turbine }}$ is calculated by the following equation (4).

$$
T_{\text {turbine }}=\frac{1}{2} \rho \mathrm{A} C_{P} V / \lambda
$$

Where $R$ is the radius of the wind turbine rotor $(\mathrm{m})$ There is a value of the tip speed ratio at which the power coefficient is maximum [2]. Variable speed turbines can be made to capture this maximum energy in the wind by operating them at a blade speed that gives the optimum tip speed ratio. This may be done by changing the speed of the turbine in proportion to the change in wind speed. Fig. 1 shows how variable speed operation will allow a wind turbine to capture more energy from the wind and fig. 2 shows the simulink model of the wind turbine. As one can see, the maximum power follows a cubic relationship. For variable speed generation, an induction generator is considered attractive due to its flexible rotor speed characteristic in contrast to the constant speed characteristic of synchronous generator.
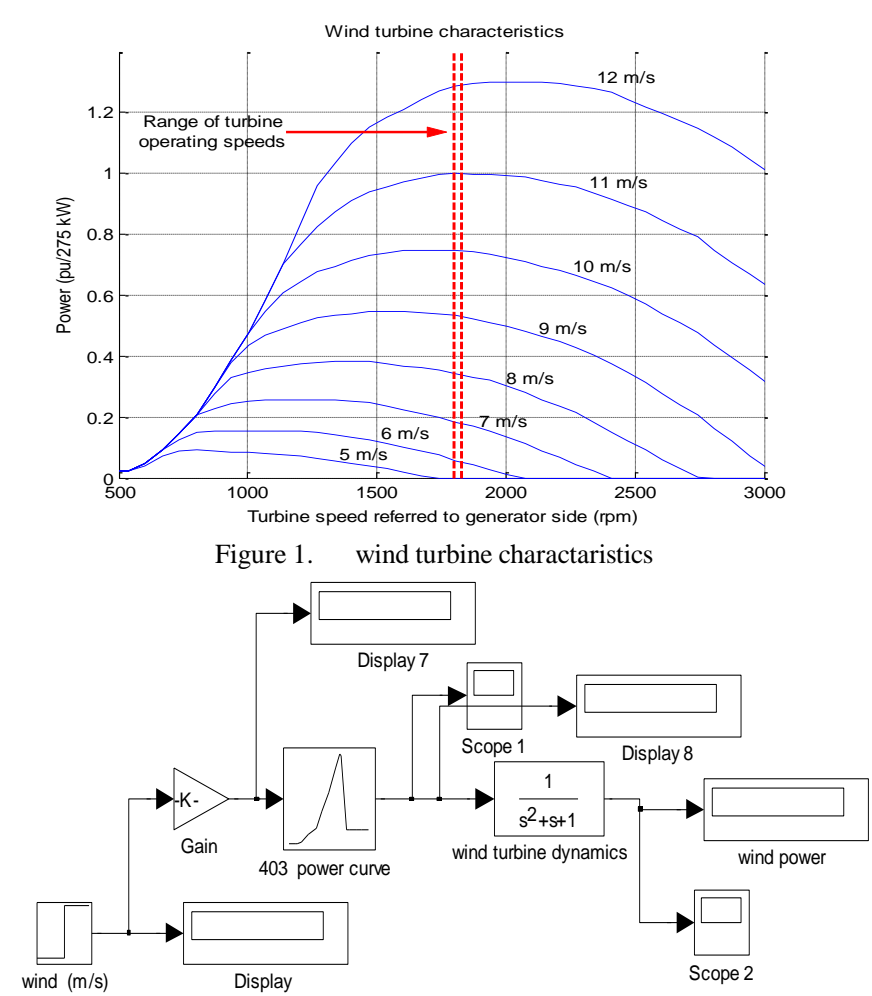

Figure 2. MATLAB Simulink model for wind turbine

\section{Dfig Modeling Using Dynamic Vector Approach}

A commonly used model for induction generator converting power from the wind to serve the electric grid is shown in figure 3 . The stator of the wound rotor induction machine is connected to the low voltage balanced three-phase grid and the rotor side is fed via the back-to-back PWM voltage-source inverters with a common DC link. Grid side converter controls the power flow between the DC bus and the AC side and allows the system to be operated in sub-synchronous and super synchronous speed. The proper rotor excitation is provided by the machine side power converter and also it provides active and reactive power control on stator and rotor sides respectively by employing vector control. DFIG can be operated as a generator as well as a motor in both sub-Synchronous and super synchronous speeds, thus giving four possible operating modes. Only the two generating modes at sub-synchronous and super synchronous speeds are of interest for wind power generation. To exploit the advantages of variable speed operation, the tracking of optimum torque-speed curve is essential. Speed can be adjusted to the desired value by controlling torque. So, an approach of using active power set point from the instantaneous value of rotor speed and controlling the rotor current iry in stator flux-oriented reference frame to get the desired active power will result in obtaining the desired values of speed and torque according to the optimum torque speed curve. The reactive power set point can also be calculated from active power set point using a desired power factor.

In the stator flux-oriented reference frame, reactive power can be controlled by controlling the $d$-axis rotor current. In stator flux-oriented control, both stator and rotor quantities are transformed to a special reference frame that rotates at an 
angular frequency identical to the stator flux linkage space phasor with the real axis ( $x$-axis) of the reference frame aligned to the stator flux vector. At steady state, the reference frame speed equals the synchronous speed. This model is called dynamic vectorized model.

The main variables of the machine in rotating frame are flux linkages $\varphi_{q s,} \varphi_{d s} \varphi^{\prime}{ }_{q r} \varphi^{\prime}{ }_{d r}$ in state space form are derived and given in [8-9]. Substituting the conditions $\omega=\omega_{\mathrm{r}}$ and $V_{q \mathrm{r}}=V_{d r}=0$ in the flux linkage equation, we get:

$\varphi_{q s}=\omega_{b} \int\left(V_{q s}-\omega_{r} / \omega_{b} \varphi_{d s}+r_{s} / x_{l s}\left(\varphi_{m q}-\varphi_{q s}\right)\right)$

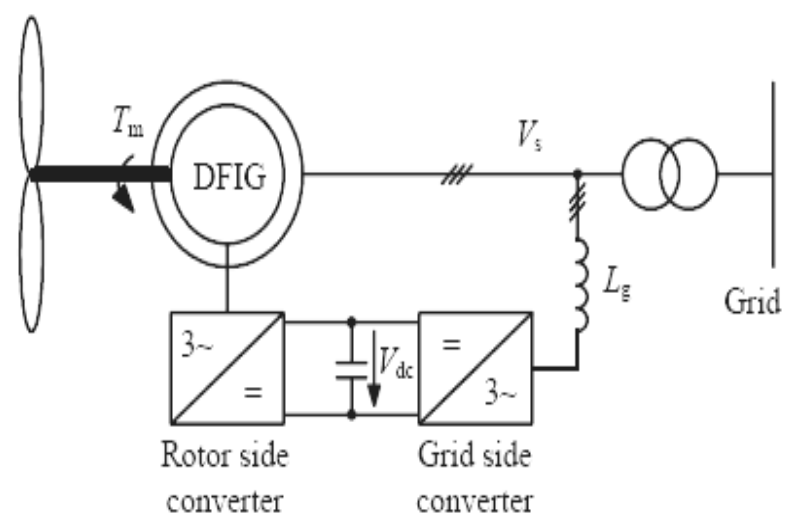

$\varphi_{d s}=\omega_{b} \int\left(V_{d s}-\omega_{r} / \omega_{b} \varphi_{q s}+r_{s} / x_{l s}\left(\varphi_{m d}-\varphi_{d s}\right)\right)$

Fig.3. Wind turbine driven DFIG

$$
\begin{aligned}
& \varphi_{q r}^{\prime}=\omega_{b} \int r^{\prime} r / x l_{r}\left(\varphi_{m q}-\varphi_{q r}^{\prime}\right) \\
& \varphi_{d r}^{\prime}=\omega_{b} \int r^{\prime} r / x l_{r}\left(\varphi_{m d}-\varphi_{d r}^{\prime}\right)
\end{aligned}
$$

The currents can now be calculated

$$
\begin{gathered}
i_{q s}=\left(\varphi_{q s}-\varphi_{m q}\right) / x_{l s} \\
i_{d s}=\left(\varphi_{d s}-\varphi_{m d}\right) / x_{l s} \\
i_{q r}^{\prime}=\left(\varphi_{q r}^{\prime}-\varphi_{m q}\right) / x_{l r}^{\prime} \\
i_{d r}^{\prime}=\left(\varphi_{d r}^{\prime}-\varphi_{m d}\right) / x_{l r}^{\prime}
\end{gathered}
$$

Solving equations ( 8-11), the $\varphi_{m q}, \varphi_{m d}$ are obtained as

$\varphi_{m q}=x_{m}\left(\varphi_{q s} / x_{l s}+\varphi_{q r}^{\prime} / x_{/ r}^{\prime}\right)$

For maintaining proper flow of variables and for convenience of simulating, the above equations are separated into the q-axis, the d-axis and the rotor circuits. In the q-axis circuit, the Equations (6), (8), (10), (12) and (14) are used to calculate, $\varphi_{q s}, \varphi_{q r}^{\prime}, i_{q s}$ and $i_{q r}^{\prime}$ respectively and $\varphi_{q s,} i_{q s}$ arc used in the calculation of electromagnetic torque. In the q-axis circuit, the Equations (7), (9), (11), (13) and (15) are used to calculate, $\varphi_{d s}, \varphi_{d r}^{\prime}, i_{d s \text { and }} i_{d r}^{\prime}$ respectively and $\varphi_{d s}, i_{q s}$ arc used in the calculation of electromagnetic torque. The rotor circuit makes use of the $\varphi_{q s}, i_{q s \text { obtained }}$ from the q-axis circuit and $\varphi_{d s}$, $i_{q s}$ obtained from the $\mathrm{d}$-axis circuit and calculates the electromagnetic torque using equation (16).The rotor circuit also takes the input mechanical torque values supplied to it and computes $W_{r} / W_{b}$ from equation (16).

$$
\varphi_{m d}=x_{m}\left(\varphi_{d s} / x_{l s}+\varphi_{d r}^{\prime} / x^{\prime} / r\right)
$$

Where, $x_{m}=1 /\left(1 / x_{m}+1 / x_{l s}+1 / x_{l r}\right)$

Now that we know $\varphi_{q s}, i_{q s}$ and $\varphi_{d s}, i_{d s}$, the electromagnetic torque can be calculated by;

$$
T_{e m}=\left(3 p / 4 \omega_{b}\right)\left(\varphi_{d s} i_{q s}-\varphi_{q s} i_{d s}\right)
$$

The equation that governs the motion of rotor is obtained by equating the inertia torque to the accelerating torque [8]:

$$
J\left(d \omega_{r m} / d t\right)=T_{e m}+T_{m e c h}-T_{\text {damp }}
$$

Expressed in per unit values, equation (13) becomes:

$$
2 H d\left(\omega_{r} / \omega_{b}\right) / d t=T_{e m}+T_{\text {mech }}-T_{\text {damp }}
$$

In equations (15) \& (16), the flux linkages are 2-phase $d-q$ axes rotating reference frame.

\section{PwM ReCTIFIER MODEL}

As stated above, the output of the rotor power (slip power) is feed to the grid through back to back PWM converters via common DC link. Machine side converter acts as a PWM rectifier and grid side converter acts as PWM inverter during the machine working in super synchronous mode. PWM rectifier is used to convert the variable magnitude, variable frequency voltage at the induction generator rotor terminals to DC voltage. The voltage $V_{r}$ at the output can be expressed by the following equation (18) in terms of the peak phase voltage $V_{d s}$ of the generator and the input transformer's turns ratio $1: \mathrm{n}$.

$$
V r=(3 \sqrt{2} / \pi)(\sqrt{3} / \sqrt{2}) V_{d s} n_{i}
$$

For smooth output DC voltage, LC filter is connected in the DC link. DC link capacitor acts as a stiff voltage source and it provides dc isolation between the two converters.Fig.4 depicts the two back-to-back connected PWM converters.

\section{Pwm Voltage Source InVerter Model}

The DC power available at the rectifier output is filtered and converted to AC power using a PWM inverter employing double edge sinusoidal modulation. The output consists of a sinusoidally modulated train of carrier opuses, both edges of which are modulated such that the average voltage difference between any two of the output three phases varies sinusoidally. Each edge of the carrier wave is modulated by a variable angle $\delta x$ and can be mathematically expressed by

$$
\delta x=M I \sin (\alpha x) \delta_{\max }(\mathrm{x}=1,2,3 \ldots 2 \mathrm{r}+1)
$$

Where $\mathrm{MI}$ is the modulation index and ranges from 0 to 1 . subscript $\mathrm{x}$ denote the edge being considered, $\mathrm{r}$ is the ratio of the carrier to fundamental frequency at the inverter output, $\alpha \mathrm{x}$ is the angular displacement of the unmodulated edge and $\delta_{\max }$ is the maximum displacement of the edge for the chosen frequency ratio $r$. 


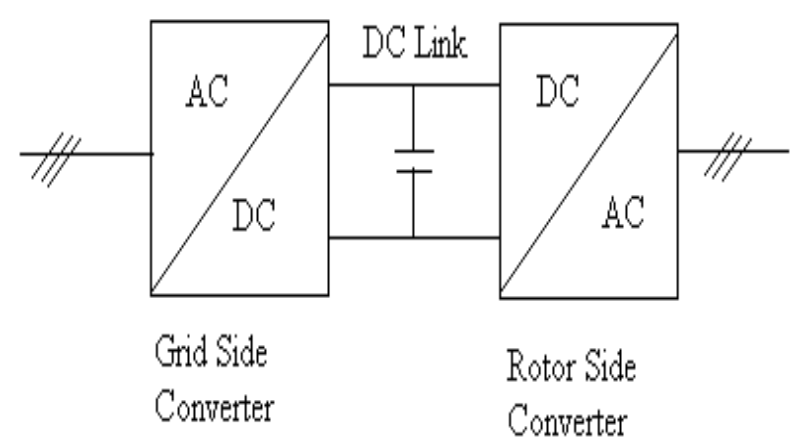

Figure 4. Two back-to-back PWM converters

In the present scheme, the inverter output voltage is controlled, while its frequency is held constant at $50 \mathrm{~Hz}$. In this range of operation, the PWM generator generates a carrier wave with frequency 15 times the fundamental frequency at the inverter output. Such a choice results in a line voltage waveform with 15 pulses per half cycle at the observed that the operating speed increases from inverter output. By modulating the carrier wave and hence the phase voltages, the fundamental and harmonic voltage content can be varied. There are 15 pulses and 15 slots of $12^{\circ}$ each. In each slot, two edges are modulated. For $100 \%$ that modulation $(\mathrm{MI}=1)$, the maximum amount by which the edge can be modulated is $\delta \max =6^{\circ}$. Any further displacement of the edge will cause the pulses in the modulated phase voltage to merge, resulting in a reduction of the number of pulses in the line voltage waveform (pulse dropping phenomenon).

\section{Results AND Discussion}

The dynamic vectorized modeling of DFIG is simulated with parameters as shown in Table 1. Vas, Vbs and Vcs are applied voltages to the stator from the grid as shown in figure 5. Due to dynamic decoupling between d-q rotor currents, active and reactive power control has to be carried out. The response of $\mathrm{d}-\mathrm{q}$ stator (rotor) currents are shown in figure 6.The wind turbine is assumed to be operated with variable speed so that it will operate in the peak power tracking mode. A varying wind speed profile is applied to the generator to investigate its performance. Due to variation of wind velocity power generated by the machine can also be changed. This is shown in the figure 7, from fig.11 for the wind velocity between 11 to $20 \mathrm{~m} / \mathrm{sec}$ the maximum has to be generated by selecting optimum tip speed ratio as a function of $\lambda$. When the wind velocity exceeds $20 \mathrm{~m} / \mathrm{sec}$ (i.e. beyond furling speed), the generator has to be disconnected from the wind turbine and supply is shutting down in order to avoid the damage in generator.Fig. 8 shows the wind velocity variation. The transient response of variable $T_{e m}$ to applied load torque is plotted in figure 9. It is seen that the electromagnetic torque reach their steady state by $0.25 \mathrm{sec}$. After that these values change only when induction generator is made to adjust its speed to operate in peak power mode. The negative value of the torque indicates that the machine is working in generating mode. The three phase PWM rectifier is simulated and the corresponding rectified DC output voltage is fed as the input to the PWM inverter. The three phase PWM rectifier is simulated with the rotor voltage of nearly
$150 \mathrm{~V}$ and it produces the corresponding output dc voltage of nearly 500 volts by the action of PWM.Fig. 10 depicts the rectified output wave forms from the rotor terminals for different wind velocities and the fig. 11 shows the DC link voltage with the value of nearly 500 V.Fig. 12 shows the sinusoidal PWM voltage source inverter waveforms which feeds ac power to the grid. The three phase PWM inverter is simulated and the corresponding switching pattern is generated to activate the IGBT switches. There are three sinusoidal reference wave each shifted by 120 degrees. A carrier wave is compared with the reference signal corresponding to a phase to generate switching pattern for the inverter switches for the switching frequency of 10 $\mathrm{KHz}$.With the output line voltage of 430 volts the rated inverter voltage of 100 volts is obtained for the modulation index of 0.9. The harmonic level in the three phase grid current wave forms are estimated by the concept of THD and it satisfies the IEEE 519-1992 standard. This is shown in the fig 13 .
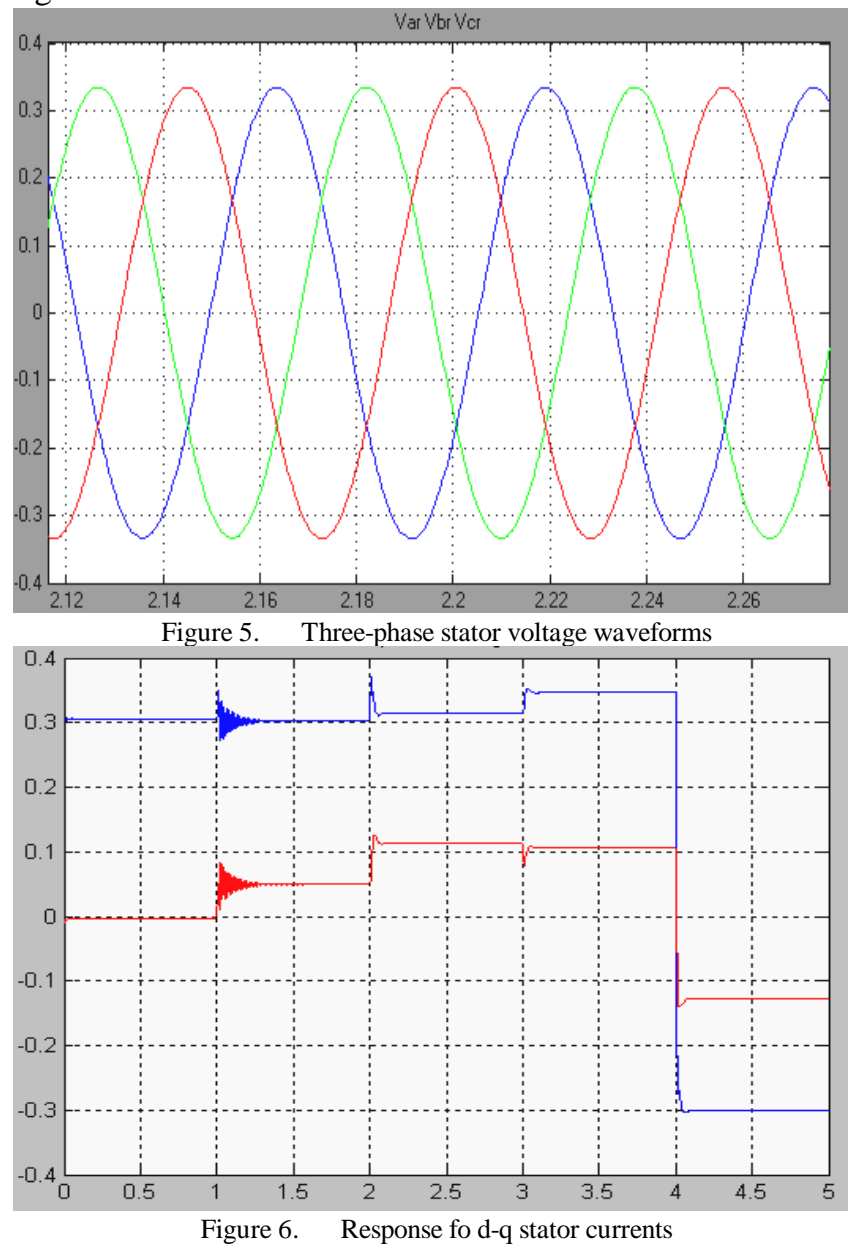


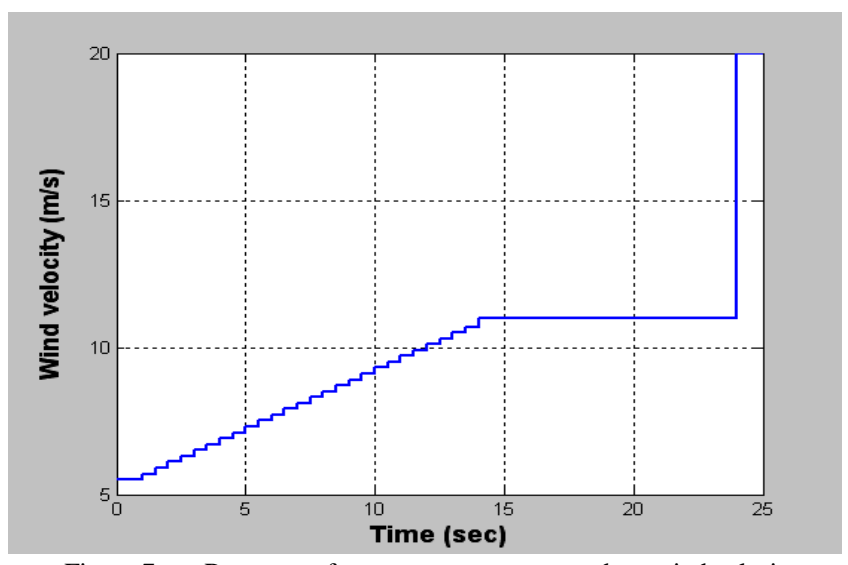

Figure 7. Response of output power corresponds to wind velosity

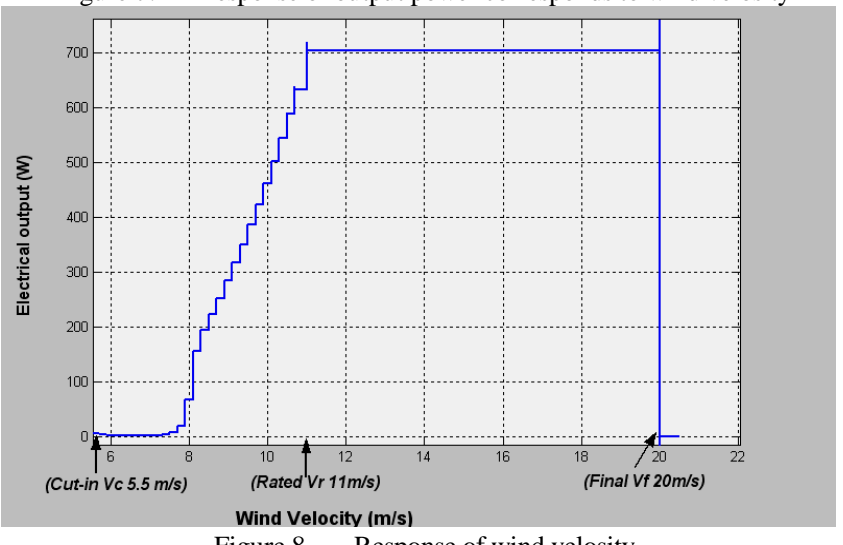

Figure 8. Response of wind velosity

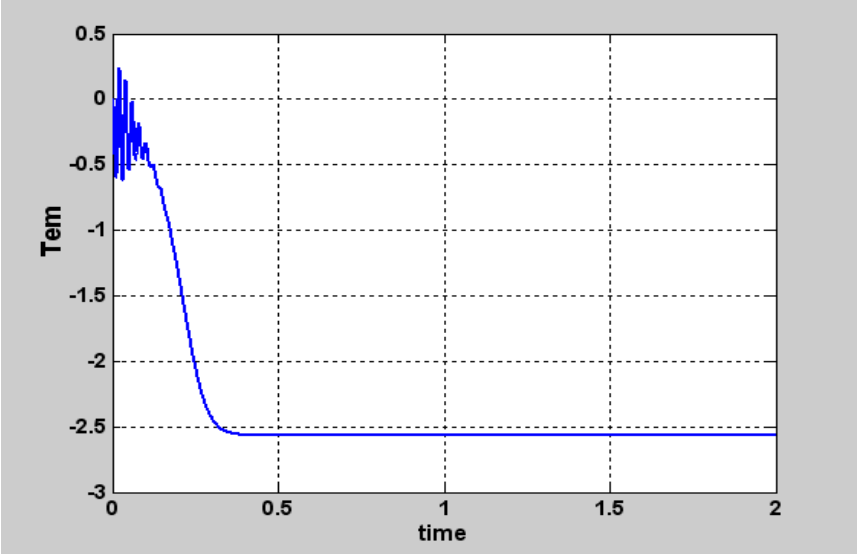

Figure 9. Response of electromagnetic torque during generating mode

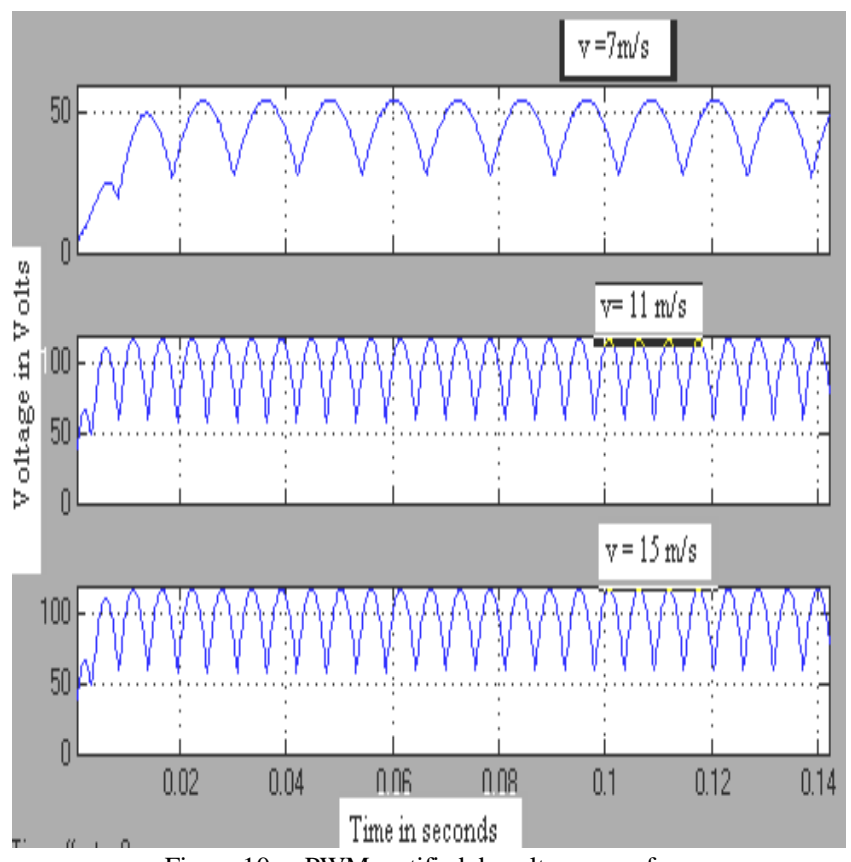

Figure 10. PWM rectified dc voltage waveforms

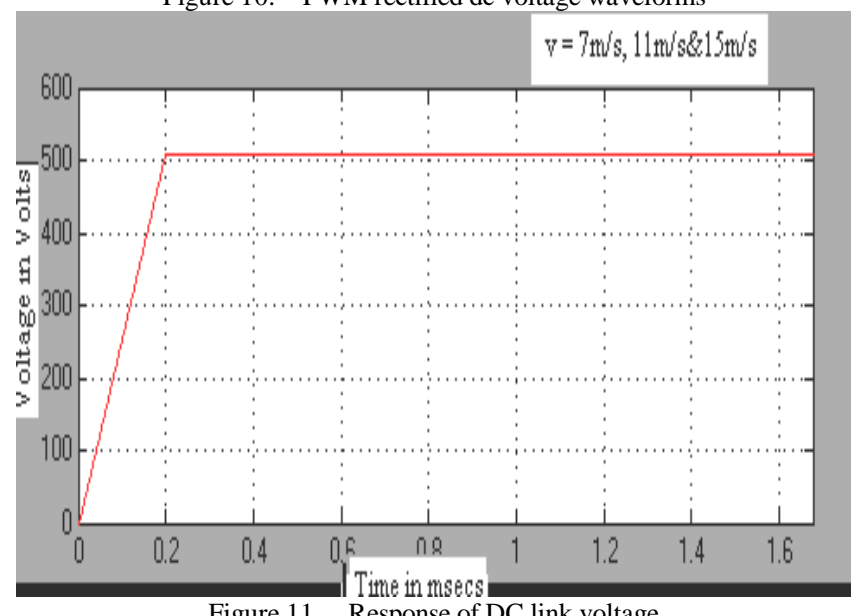

Figure 11. Response of DC link voltage 


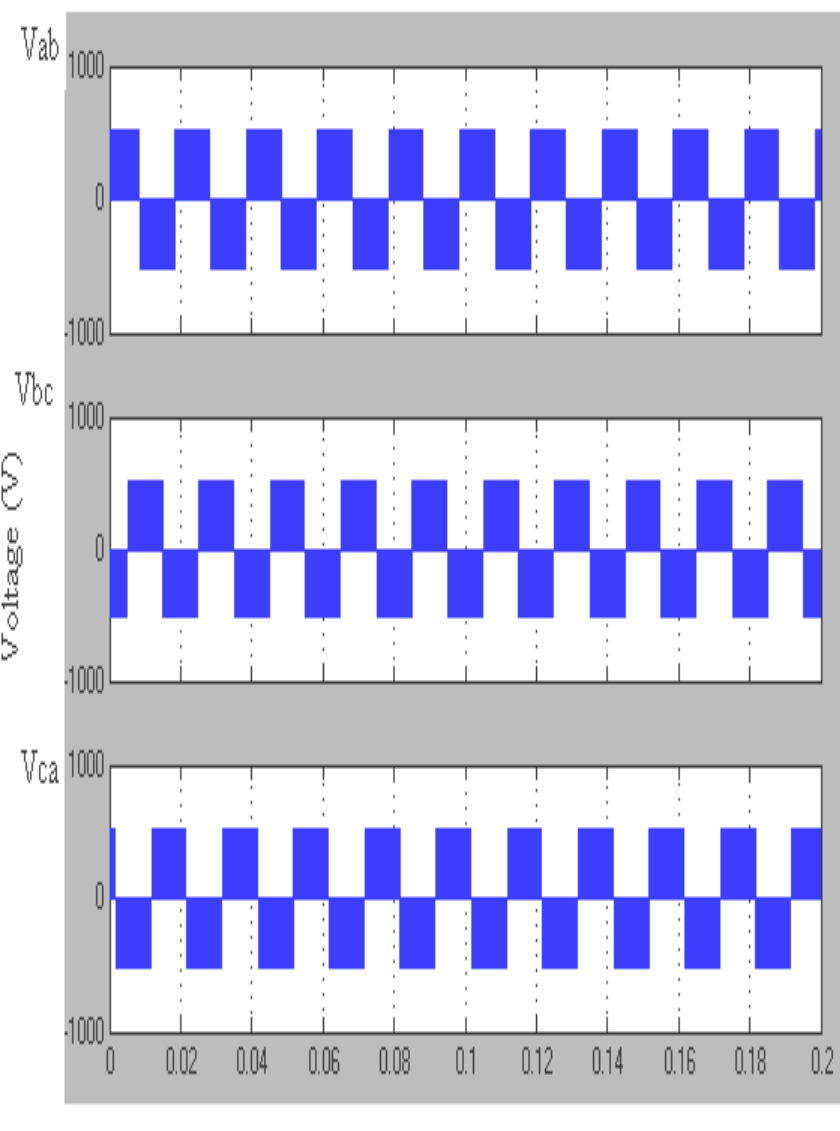

Time (s)

Figure 12. Three-phase SPWM inverter output waveforms FFT window: 2 of 90 cycles of selected signal

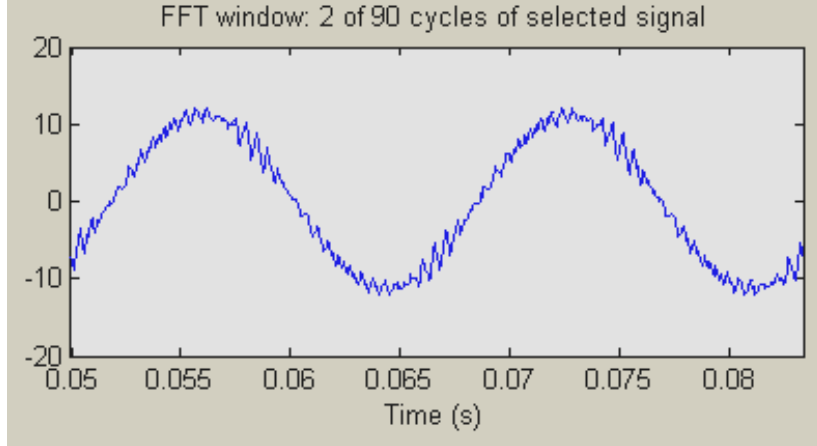

Fundamental $(6 \mathrm{OHz})=11.22, \mathrm{THD}=8.31 \%$

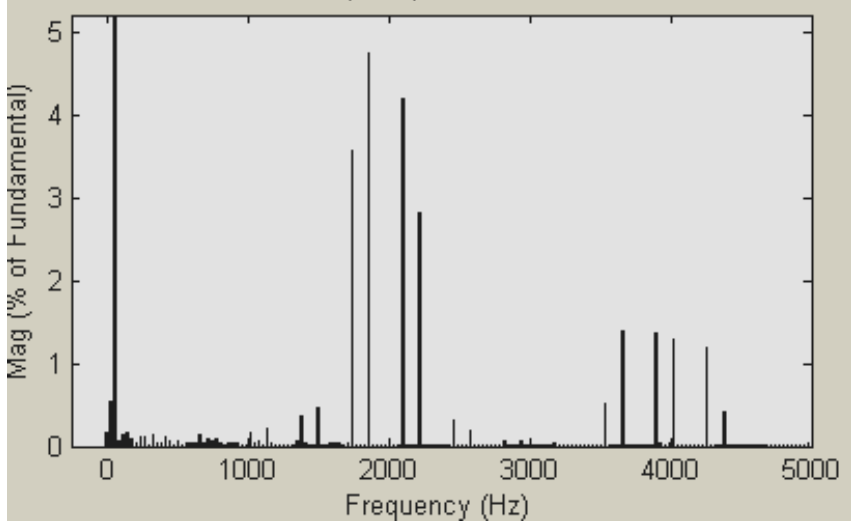

Figure 13. THD level for grid current waveforms

\section{CONCLUSION}

This paper has presented the modeling and simulation of wind turbine driven doubly-fed induction generator which feeds power to the utility grid. Wind turbine modeling has been described in order to extract maximum possible mechanical power from the wind according to the wind velocity and tip-speed ratio. DFIG model has been described based on the vectorized dynamic approach and this model can be applicable for all types of induction generator configurations for steady state and transient analysis. However the choice of the reference frame will affect the waveforms of all $\mathrm{d}-\mathrm{q}$ variables. It will also affect the simulation speed and in certain cases the accuracy of the results. Generally the conditions of operation will determine the most convenient reference frame for analysis. The power flow control in the DFIG can be obtained by connecting two back to back PWM converters between rotor and utility grid. The PWM rectifier model and SPWM inverter model has been described and these two converters provides bi-directional power flow with reduced power rating.THD levels of the inverter output voltage has been estimated using fast Fourier transform which satisfies the IEEE 519-1992 standard. The steady state and Transient analysis of wind turbine driven DFIG will be described in the next paper.

\section{APPENDIX}

5-KW Induction wind turbine model parameters.

\begin{tabular}{|l|l|}
\hline Number of poles & 4 \\
\hline Rated Speed & $1800 \mathrm{rpm}$ \\
\hline Rated Voltage & $200 \mathrm{~V}$ \\
\hline Rated Output Power & $750 \mathrm{~W}$ \\
\hline Stator winding resistance & $3.35 \mathrm{ohm}$ \\
\hline Stator leakage reactance & $2.616 \mathrm{ohm}$ \\
\hline Rotor resistance as referred to stator & $1.99 \mathrm{ohm}$ \\
\hline Rotor leakage reactance & $2.616 \mathrm{ohm}$ \\
\hline Rotor inertia & $0.1 \mathrm{Kgm}$ \\
\hline Cut-in speed $V c$ & $5.5 \mathrm{~m} / \mathrm{s}$ \\
\hline Rated speed $V_{R}$ & $11 \mathrm{~m} / \mathrm{s}$. \\
\hline Furling or cut-out speed $V_{F}$ & $20 \mathrm{~m} / \mathrm{s}$ \\
\hline Gear ratio K & 0.001 \\
\hline
\end{tabular}

\section{REFERENCES}

[1] S. Muller, M. Deicke and R. W. De Doncker, "Doubly fed induction generator systems for wind turbine," IEEE Industry Applications Magazine, Vol.3, , pp. 26-33.2002

[2] R. Pena, J. C. Clare and G. M. Asher, "Doubly fed induction generator using back-to-back PWM converts and its application to variable speed wind-energy generation," IEE Proceedings Electrical Power Application, Vol.143, pp. 231-241.1996

[3] A. Tapia, G. Tapia, J. X. Ostolaza and J. R. Saenz, "Modeling and control of a wind turbine driven doubly fed induction generator," IEEE Transactions on Energy Conversion, Vol.18, pp. 194- 204.2003

[4] Yazhou Lei, Alan Mullane, Gordon Lightbody, and Robert Yacamini, "Modeling of the Wind Turbine With a Doubly Fed Induction Generator for Grid Integration Studies,” IEEE Transactions on Energy Conversion, Vol. 21(1), pp.257-264.2006

[5] V.Akhmatoy and H.Krudsen, "Modelling of windmill induction generator in dynamic simulation programs," Proc. IEEE Int. Conference on Power Technology, Budapest,Hungary, paper No. 108.Aug 1999.

[6] H.Li and Z.Chen, "Overview of generator topologies for wind turbines," IET Proc. Renewable Power Generation, vol. 2, no. 2, pp. 123-138, Jun.2008.

[7] Lucian Mihet-Popa, Frede Blaabrierg, "Wind Turbine Generator Modeling and Simulation Where Rotational Speed is the Controlled Variable", IEEE Transactions on Industry Applications, Vol. 40.No.1, January/February 2004.

[8] B.H.Chowary, Srinivas Chellapilla, "Doubly-fed induction generator for variable speed wind power generation" Transactions on Electric Power System Research, Vol.76,pp. 786-800, Jan 2006. 
[9] Sandy Smith,Rebecca Todd and Mike Barnes "Improved Energy Conversion for Doubly- Fed Wind Generators", Proceedings of IAS 2005, pp. 7803-9208, June 2005.

[10] Jamel Belhadj and Xavier Roboam "Investigation of different methods to control a small variable- speed wind turbine with PMSM drives", ASME Transactions on Journal of Energy Resources Technology, Vol. 129 / 201 , September 2007.

B.Chitti Babu received the B.E degree in Electrical \& Electronics Engineering from Madurai Kamraj University, India and M.E degree in Power Electronics \& Drives from Anna University Chennai, India in 2003 and 2006 respectively. He has been with National Institute of Technology Rourkela, India as a Faculty in the Department of Electrical Engineering since 2007. He has presented nearly 20 papers in International and National level conferences and received three best paper awards. His research interests are power electronics applications in distributed power generation and analysis of power converters. He is a member of IEEE (USA), Student Member of IET (UK) and Member of ISTE (India).

Kanungo Barada Mohanty has received B.E. degree from University College of Engineering, Burla; M.Tech. and Ph.D. degrees from Indian Institute of Technology, Kharagpur in the years 1989, 1991 and 2002 respectively, all in Electrical Engineering. He is a faculty member of Electrical Engg. Dept, National Institute of Technology, Rourkela since 1991, and currently serving as Assistant Professor. He has seven journal publications and several papers in various international and national conferences, all in the field of power electronic drives. His research interests include control and estimation in induction motor drive and wind turbine driven induction generator. Dr. Mohanty is a member of IEEE (USA), The Institution of Engineers (India), Solar Energy Society of India, System Society of India, and Indian Society of Technical Education. 